Арыстан А. Ж. ${ }^{1}$, Хамзина Е. Т. ${ }^{1}$, Бенберин В. В. ${ }^{1}$, Фетцер А. В. ${ }^{2}$, Беленков Ю. Н. ${ }^{3}$

${ }^{1}$ Больница Медицинского центра УА Президента Республики Казахстан, Нур-Султан, Казахстан

${ }^{2}$ ГБУЗ «ГКБ № 52 Аепартамента зАравоохранения г. Москвы», Москва, Россия

${ }^{3}$ ФГАОУ ВО Первый Московский госуАарственный меАицинский университет им. И. М. Сеченова МинзАрава России (Сеченовский Университет), Москва, Россия

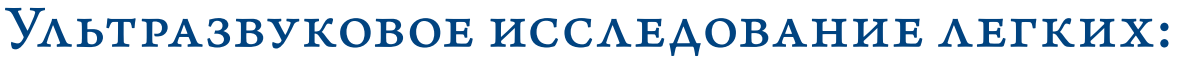 НОВЫЕ ВОЗМОЖНОСТИ ААЯ КАРАИОАОГА
}

Обзор митературы посвящен ультразвуковому исследованию (УЗИ) мегких, которое является полезным дополнением к трансторакальной эхокардиографии (ЭхоКГ) и по Аиагностической ценности превосходит рентгенографию органов груАной клетки. Акустическое мегочное окно остается всегАа открытым и в большинстве случаев позволяет получить изображения высокого качества. Аля кардиолога основные точки приложения метода - это определение плеврального выпота и мегочного застоя. Метод обладает рядом преимуществ: не занимает много времени, имеет низкую стоимость, портативность и Аоступность, возможность обследования в режиме реального времени, отсутствие раАиации, хорошую воспро-

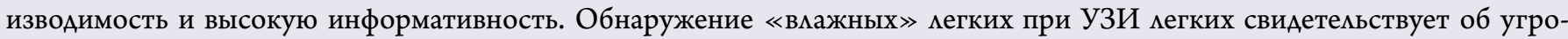
жающей острой Аекомпенсации серАца еще заАолго Ао появления кАинических, аускультативных и рентгенологических признаков мегочного застоя. Современная ЭхоКГ Аолжна вкАючать обследование серАца и мегких в рамках одного интегрированного УЗИ.

Ключевые слова

Аля цуитирования

Автор дяя переписки

\section{Умьтразвуковое исслеАование мегких, кардиология}

Arystan A.Zh., Khamzina Y.T., Benberin V.V., Fettser D.V., Belenkov Yu.N. Lung Ultrasound: new Opportunities for a Cardiologist. Kardiologiia. [Russian: Арыстан А.Ж., Хамзина Е.Т., Бенберин В.В., Фетцер А.В., Беленков Ю.Н. УАьтразвуковое исслеАование мегких: новые возможности Аля карАиолога. КарАиология.] 2020;60(1):81-92.

Арыстан Аяна Жалгаскаликызы. E-mail: arystan.ayana@gmail.com

\section{ВвеАение и исторические преАпосымки}

На протяжении многих мет умьтразвуковое исследование (УЗИ) мегких считалось нецелесообразным, и до сих пор в учебной митературе существет стандартное утвержАение, что «поскольку умьтразвуковая энергия мгновенно рассеивается в воздухе, визуализация паренхимы мегких методом умьтразвуковой Аиагностики не преАставмяется возможной» $[1]$. ОАнако это не совсем так, и новые исследования показывают, что УЗИ мегких позволяет Получить УАивительные АивиАенАы в некоторых сложных клинических ситуациях: от отека мегких Ао интерстициального фиброза мегких, от острого респираторного Аистресс-синарома Ао плеврального выпота и мегочной тромбоэмболии $[2,3]$. При отеке мегких нацичие жиАко-

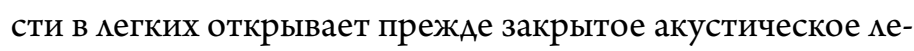
гочное окно и позволяет увидеть внутреннюю картину застоя в мегких, которая может быть прямо отображена и полуколичественно оценена [4-7].

При УЗИ нормахьного мегкого еАинственной структурой, отображающейся на экране монитора, явцяется плевра, которая визуализируется как гиперэхогенная миния. Аиния плевры движется синхронно с актом дыхания, и это Аинамическое горизонтацьное Авижение называется «скольжением» мегкого [3].

Кроме того, имеются некоторые гиперэхогенные горизонтальные минии, возникающие через равные промежутки времени от минии плевры: А-линии. В сочетании со «скольжением» мегкого эти артефакты реверберации преАставцяют собой признак нормахьного ими чрезмерного содержания воздуха в альвеолярных пространствах (рис. 1) [8].

КогАа содержание воздуха уменьшается и плотность мегких увеличивается из-за наличия в них экссудата, транссудата, комлагена, крови и т.А., акустическое сопротивце-

Рисунок 1. Сонографическое

изображение наполненного возАухом мегкого

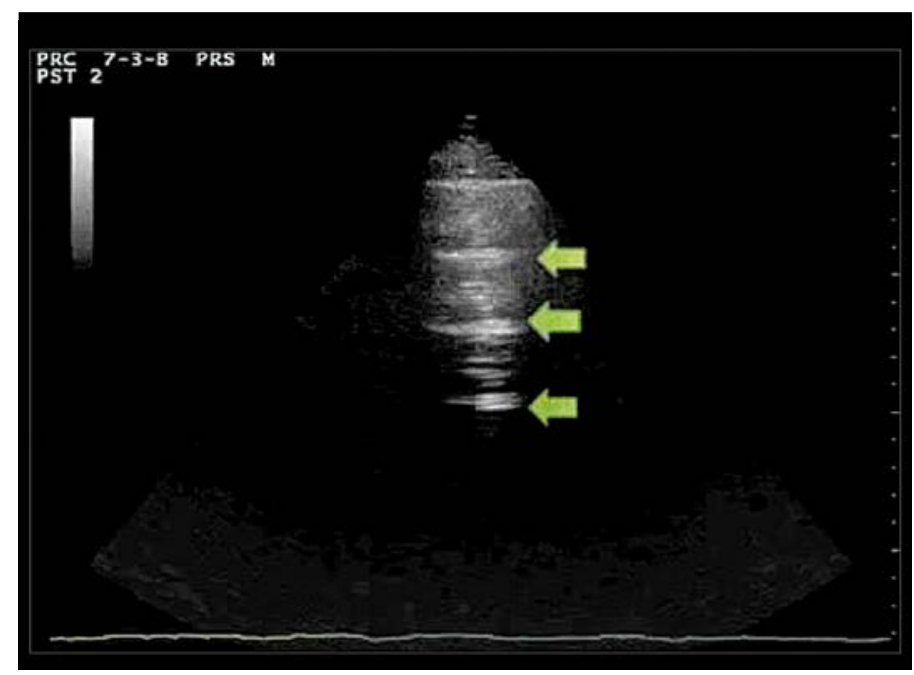

Стрелки обозначают А-линии. Выше А-линий визуализируется миния пиевры с ее горизонтальным Авижением - «скольжение» мегкого. 
Рисунок 2. Сонографическое изображение множественных В-линий (обозначены белыми стрелками)

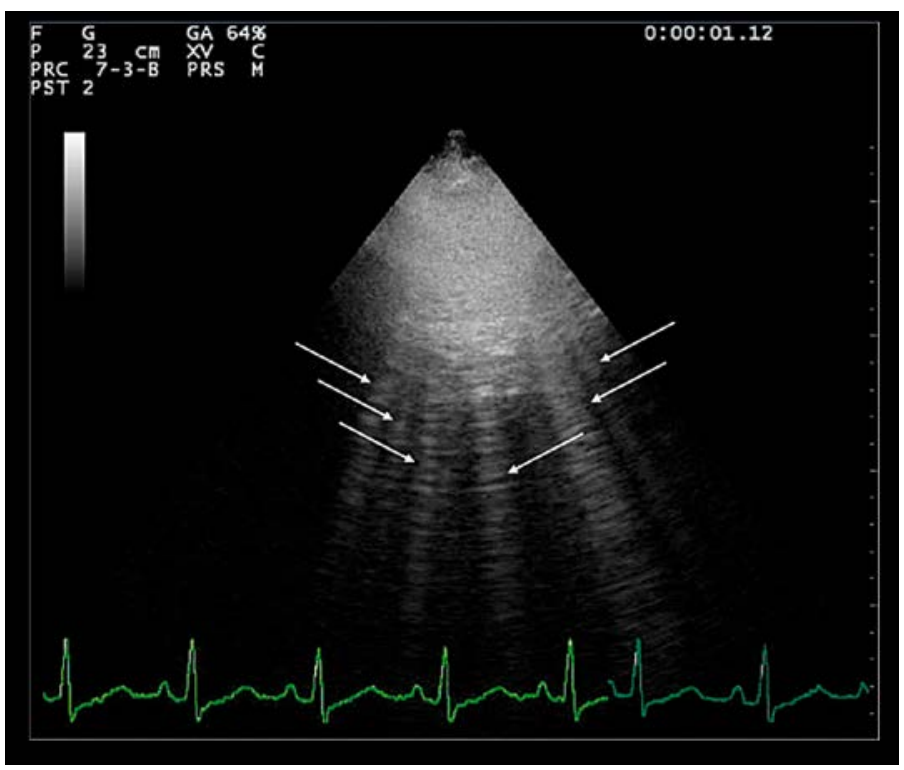

ние межАу Аегкими и окружающими тканями уменьшается, и ультразвуковой куч может неоднократно и частично отражаться от более глубоких зон. Этот феномен создает некоторые гиперэхогенные артефакты вертикальной реверберации, известные как В-линии (рис.2). Последние принаАлежат к семейству артефактов по типу хвоста кометы, хорошо известные в УЗИ брюшной полости [9].
В-линии определяются как Аискретные, похожие на мазер артефакты, возникают из плевральной минии, распространяются Ао конца экрана без выцветания, стирают А-линии и Авижутся синхронно со «скольжением» мегких $[10,11]$. Множественные В-линии считаются сонографическим признаком мегочного интерстициального синарома, и их количество увеличивается оАновременно с уменьшением содержания возАуха и увеличением пиотности мегких $[12,13]$.

КогАа аэрация мегких снижается еще больше, например, при наличии уплотнений, акустическое окно становится полностью открытым, что позволяет увидеть изображение мегкого как твердую паренхиматозную ткань, анацогично изображению при УЗИ печени ими семезенки (рис. 3).

Начиная с 80-х годов XX века появимись несколько отАельных сообщений о В-линиях $[14,15]$. В 1994г. R. Targhetta и соавт. впервые описали наличие B-линий при патологии мегких [16]. Французский реаниматолог D. Lichtenstein впервые установил 2 основные структурные корреляции В-линий, сравнивая результаты УЗИ мегких с компьютерной томографией (КТ) груАной кметки [7]. Аанные КТ показали, что В-линии коррелировали с утолщением субплевральных междолевых перегородок при мегочном интерстициальном отеке и с фиброзным утолщением при мегочном фиброзе. Так зародилась со-

Рисунок 3. Физическая основа умьтразвукового исслеАования мегких: чем меньше возАуха в мегких, тем мегче определить патологические изменения методом умьтразвукового исследования

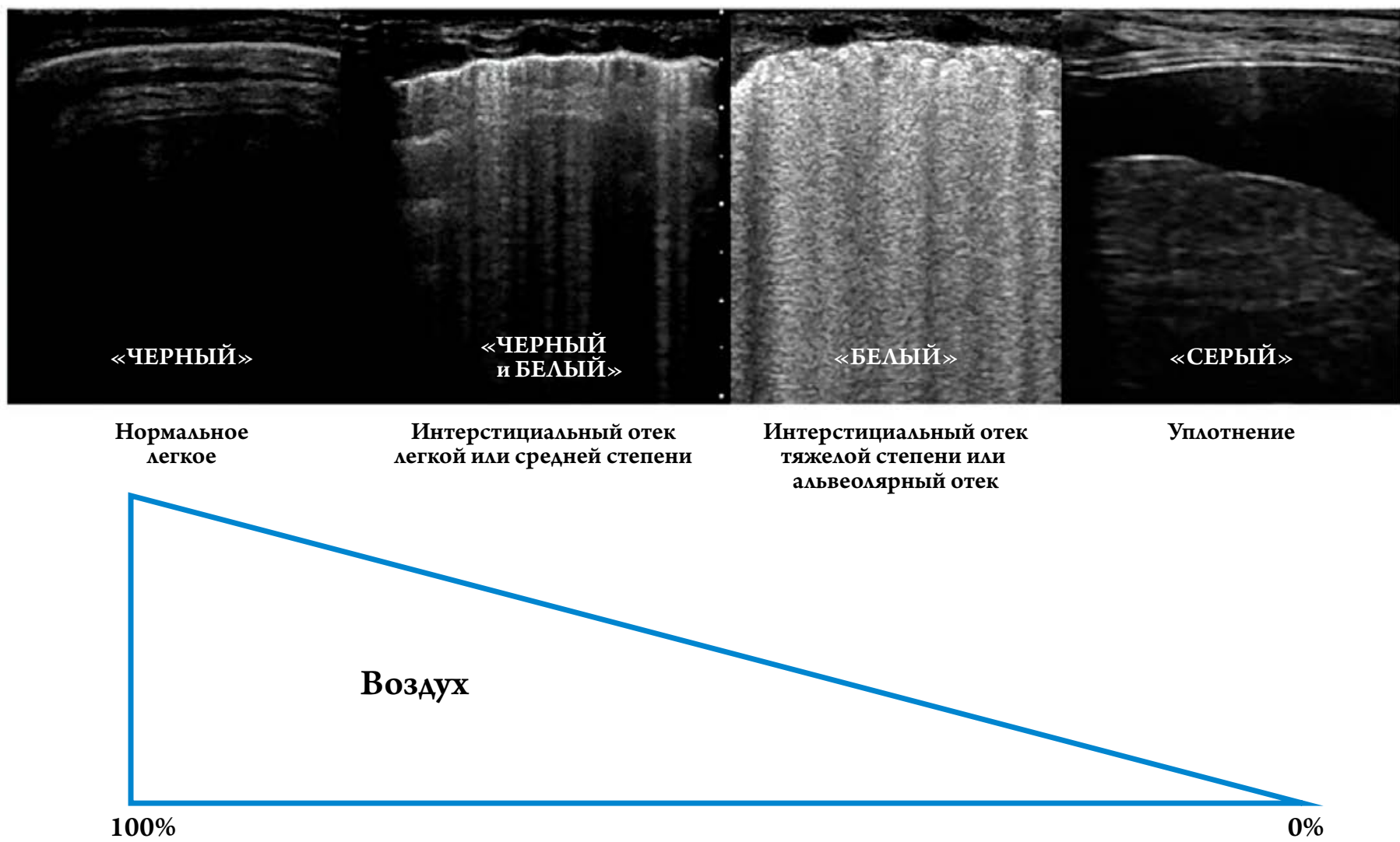


временная эра УЗИ кегких. На самом деле УЗИ кегких уже много мет использовалось Аля оценки плеврального выпота, но признание информации, предоставленной артефактами, сформировало совершенно новый поАхоА [17].

Кардиологам потребовалось 50 мет практики трансторакальной эхокардиографии (ТТ-ЭхоКГ), прежде чем им УАалось савинуть Аатчик на несколько сантиметров от карАиологического акустического окна, чтобы обрести УАивительно новый Аиагностический мир УЗИ мегких. В 2004 г. Е. Picano и Jambrik в маборатории эхокардиографии Института кминической физиологии Национального научно-исследовательского совета Италии перенесли УЗИ мегких из отдемения интенсивной терапии в отдемение карАиологии, описав корреляцию межАу содержанием внесосудистой жидкости в мегких, оцененной с помощью рентгенографии груАной кметки, и комичеством В-линий, обнаруженных при УЗИ кегких [18]. В последующие годы была предоставлена экспериментальная $[9,19]$, клиническая [20-23] и методологическая [24] валидация В-миний.

В-линии явАяются оАними из самых простых и воспроизводимых признаков, распознаваемых при УЗИ серАечно-сосудистой системы, считаясь уровнем «детского сада» в учебной программе ЭхоКГ, тогАа как опредемение мокальных нарушений сократимости стенок явмяется бомее сложным - «университетским» уровнем [17].

Аиагностическая информация, извлекаемая с помощью УЗИ мегких, преАставмяет несомненный кАинический интерес Аля кардиолога, которому хорошо известна прогностическая и терапевтическая значимость внесосудистой жидкости в мегких. И как оценка количества жидкости в мегких в реальном времени может преАоставить информацию, Аополняющую традиционные методы, основанные на физическом обследовании и рентгенографии груАной кметки дмя выявмения мегочного застоя. Несмотря на то что только ограниченная часть мегочной паренхимы Аоступна визуализации, эта небольшая зона критически важна, поскольку наиболее острые и опасные Амя жизни поражения соприкасаются с плеврой: плевральные выпоты, пневмоторакс и острый интерстициальный синдром в 100\% скучаев, а уплотнение ткани мегкого - в 98,5\% [25].

Кроме того, реаниматологи и кардиологи часто работают с одними и теми же пациентами и обычно существует тесная пространственная связь межАу отделениями реанимации и кардиологическими блоками интенсивной терапии. Этот Аогистический момент теоретически АОАжен способствовать распространению таких инновационных практик [26].

УЗИ мегких (также называется УЗИ грудной кметки или сонография грудной кметки, но эти названия могут включать средостение и серАце) по сравнению с Аругими виАами исслеАований имеет целый ряА преимуществ: мо- бильность, отсутствие ионизирующей радиации, мгновенный результат, возможность применения мюбого виАа аппарата и датчика. Перечисленные достоинства метода особенно важны А^я пациентов, нужАающихся в постоянном и динамическом мониторировании патомогии мегких и/или уровня жидкости, особенно в пацатах интенсивной терапии и реанимации [27].

В настоящее время при компмексном, ограниченном или прицельном обследовании пациента УЗИ кегких готово Аля встраивания в стандартную ТТ-ЭхоКГ от полнофункциональной платформы, выполненной сертифицированными специалистами по ЭхоКГ, Ао портативного устройства, используемого неспециалистом по ЭхоКГ. В Аругих областях кардиологии очень сложно найти такое большое количество диагностических преимуществ с таким незначимым объемом инвестиций с точки зрения технологии, обучения и времени [17].

\section{Методология исследования}

Аля карАиолога УЗИ мегких явмяется Аополнением к ТТ-ЭхоКГ и Аолжно быть цеменаправленным, быстрым, без мишних затрат времени, отдельного протокола и дополнительной стоимости. Среднее время комплексного сканирования серАца при ТТ-ЭхоКГ составмяет 4045 мин, а сканирование мегких в цемях выявмения плеврального выпота или отека мегких займет еще 2 мин [25].

Амя проведения УЗИ мегких может быть использован мюбой 2D-ультразвуковой аппарат с мюбым видом датчика (умьтразвуковой аля конвергентного сканирования, минейный, конвексный, микроконвексный). Аоппиер, вторая гармоника или контрастное вещество не требуются. Более того, Амя исследования могут использоваться как полностью оборудованный, так и портативный аппараты. В зависимости от показаний поможение пациента во время исследования может быть мюбым: межа на спине, полулежа или сиАя [28].

\section{Техника}

Акустическое мегочное окно всегАа открыто Аля УЗИ, Ааже когАа сердечное акустическое окно закрыто Аля ТТЭхоКГ [8]. Вся грудная кметка может быть мегко просканирована расположением ультразвукового Аатчика проАольно (перпенАикулярно ребрам) или поперечно (вАоль межреберных пространств) [13].

Предложено несколько специфических методов УЗИ мегких: сканирование передней и боковой поверхностей груАной клетки может быть получено с правого и мевого гемиторакса, со второго по четвертое (с правой стороны по пятое) межреберные промежутки и от парастернальной до задней подмышечной минии - всего 28 зон $[13,18]$. Задняя поверхность грудной кметки сканируется вдоль паравертебральной, мопаточной и задней подмышечной миний $[13,27]$. 
В экстренных случаях может быть использован метоА G. Volpicelli и соавт. [29] с исследованием 8 сканируемых зон гемиторакса - 4 справа и 4 слева: верхние и нижние передние и матеральные (боковые) поверхности грудной кметки [27].

У пациента в критическом состоянии с острой дыхательной недостаточностью более быстрое сканирование Авух передних зон груАной клетки будет достаточным Аля искмючения интерстициального синарома вслеАствие острого кардиогенного отека мегких. ОАнако такое прицельное переднее сканирование, высокоточное в критической ситуации, может быть недостаточным у пациентов без тяжемой одышки, поскольку определение В-линий на переАней поверхности грудной кметки обычно слу-

Рисунок 4. В-минии и их подсчет

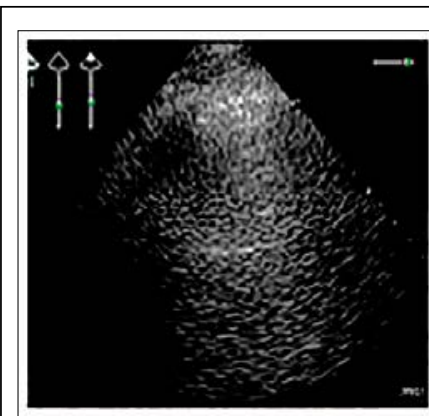

В-линии отсутствуют

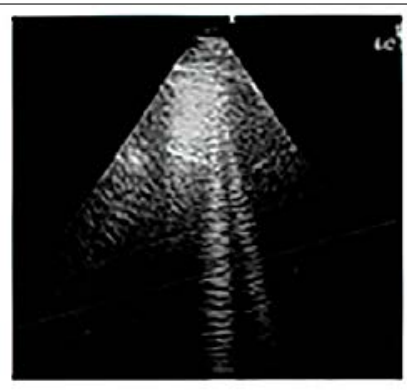

Аве В-минии

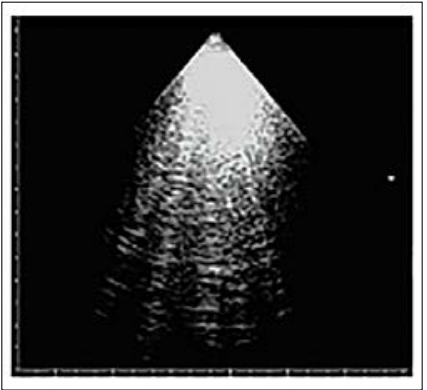

Пять В-миний

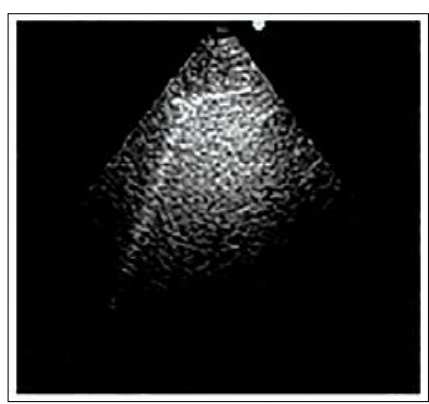

ОАна В-линия

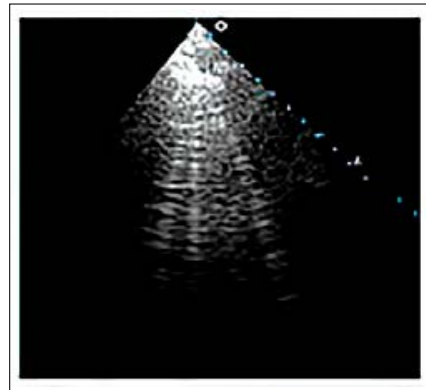

Три В-минии

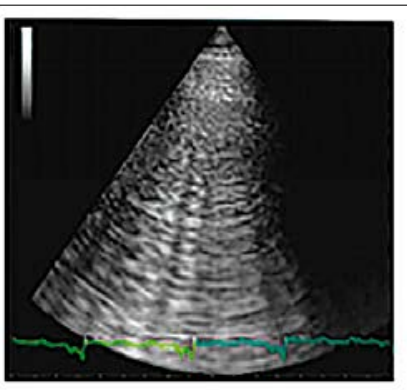

Полностью белый экран $=10 \mathrm{~B}-$ иний
КажАая гиперэхогенная вертикальная дорожка, распространяющаяся от Аинии плевры до нижнего края экрана, преАставляет отдельную В-линию. При использовании кардиомогического Аатчика считается, что полностью белый экран соответствует предельному значению В-линий: 10. жит признаком более тяжемой степени мегочного застоя при сердечной недостаточности $(\mathrm{CH})[30]$.

При оценке В-линий, наиболее информативного признака УЗИ мегких Аля кардиолога, сумма В-линий, обнаруженных в каждой зоне сканирования, дает бам, обозначающий объем внесосуАистой жидкости в $е г-$ ких. В кажАой зоне сканирования число В-линий может быть от 0 Ао 10. Ноль подразумевает полное отсутствие В-линий в исследуемой зоне, в то время как полностью белый экран при сканировании одной зоны карАиологическим Аатчиком соответствует 10 В-линиям (рис. 4) [4]. В клинических целях количество В-линий можно кмассифицировать от мегкой Ао тяжелой степени, подобно тому, как это Аелается Аля большинства ЭхоКГ-параметров [4] (табл. 1). В-линии имеют очень хорошую вариабельность результатов у разных исследователей и у одного исследователя - окомо 5 и $7 \%$ соответственно [18].

Определение плеврального выпота явмяется наиболее устоявшимся применением УЗИ кегких [3, 31]. С помощью УЗИ мегких можно отличить выпот в плевральной полости от ателектаза, уплотнений, масс или высокого стояния купола диафрагмы, которые иногда трудно размичить при рентгенографии грудной кметки [13]. УЗИ мегких Аля Аиагностики плеврального выпота особенно ценно у пациентов, находящихся в критическом состоянии, Аемонстрируя более высокие чувствительность и надежность, чем рентгенография грудной кметки у постели больного [32], которая редко выявмяет небольшие по объему выпоты и может пропустить скопление жидко-

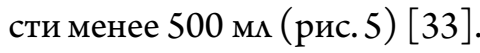

Таблица 1. Количественная оценка В-линий

\begin{tabular}{c|c|c} 
Баммы & Число В-линий & Внесосудистая жидкость в мегких \\
\hline 0 & $\leq 5$ & Нет признаков \\
\hline 1 & $6-15$ & Аегкая степень \\
\hline 2 & $16-30$ & Умеренная степень \\
\hline 3 & $>30$ & Тяжелая степень
\end{tabular}

Рисунок 5. Рентгенограмма органов грудной клетки с умеренным количеством выпота в правой плевральной полости (А) и результаты ультразвукового исслеАования плевральной полости справа этого же пациента с выпотом окомо 2 см (Б)

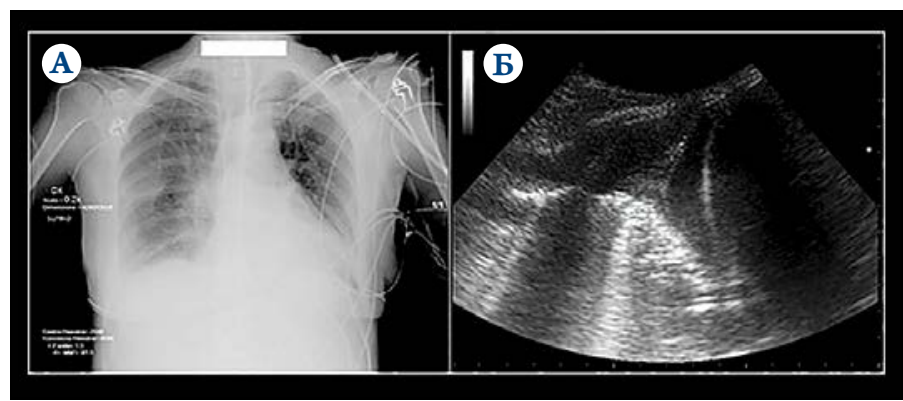


С помощью УЗИ мегких можно обнаружить выпот, оценить его объем, предоставить информацию о его природе и указать подходящую область Аля торакоцентеза. Кроме того, УЗИ мегких превосходит КТ в диагностике сложного выпота из-за способности различать перегородки и фибрин внутри жидкости [34].

Как уже отмечалось, УЗИ мегких можно проводить в положении больного стоя, сиАя или межа без существенных размичий в результатах. ОАнако при обследовании в динамике положение (сиАя или межа) Аолжно отслеживаться, поскольку плевральная и мегочная жиАкость меняется с изменением положения тела.

При использовании упрощенной схемы сканирование мегкого может быть проведено менее чем за 2 мин. УЗИ мегких остается воспроизводимым и надежным исслеАованием при любых гемодинамических и вентиляционных состояниях, в отличие от информации при ТТ-ЭхоКГ. Она может ухудшаться при острых состояниях из-за гипервентимяции и тахикардии, что делает визуализацию и интерпретацию некоторых параметров (например, мокальная сократимость стенок, Аиастолическое наполнение) более сложной [25].

\section{Цемь метола}

Амя кардиолога УЗИ мегких в основном нацемено на изменение уровня жидкости в паренхиме мегкого (застой в мегких в покое и при нагрузке) или плевральной полости (пиевральный выпот).

\section{Сердечная недостаточность}

Последовательность событий, приводящих к острому отеку мегких при СН, концептуально может быть сформулирована как каскаА жидкости в мегких, последовательность которого быма раскрыта с изобретением УЗИ кегких [35]. Инициирующими событиями каскада явмяются увеличение конечного Аиастолического Аавления мевого жекудочка ( $Ж$ ) и Аавмения заклинивания в капимлярах мегочной артерии - $\Lambda$ А (гемодинамический застой), в конечном счете, приводя к Аисбалансу равновесия Старлинга в альвеолярно-капимлярном барьере, что является обязательным условием Аля повышения накопления жидкости в мегких. МежАу гемодинамическим и клиническим мегочным застоем существует промежуточное событие интерстициальный застой в мегких, обнаруживаемый при УЗИ мегких в виде нескольких В-линий [36], биофизически связанных с повышенным соотношением воАы и воздуха на единицу объема мегких в субплевральных междолевых перегородках [13].

Согласно послеАним клиническим рекоменАациям Европейского общества кардиологов (ЕОК) по диагностике и мечению острой и хронической $\mathrm{CH}$ [37], рентгенография органов груАной кметки явмяется основным мето-
Аом Аля Аиагностики внесосудистой жиАкости в Аегких, несмотря на ее известные ограничения [38]. Проведение рентгенологического исследования требует наличия радиологического оборудования, подразумевает облучение пациента, а интерпретация результатов в значительной степени зависит от квалификации оператора и, самое важное, - низкая чувствительность метоАа, т.е. возможность обнаруживать только значимые изменения водного статуса без определения минимального повышения или снижения количества жидкости в интерстициуме [39]. Более того, по данным клинических исследований, отсутствие рентгенологических признаков мегочного застоя не исключает повышенное давление наполнения $\Lambda Ж$ и, соответственно, повышенного давмения заклинивания в $\Lambda$ A $(A 3 \Lambda$ A). Именно измерение $A 3 \Lambda$ А с помощью катетера является «золотым стандартом» в Аиагностике отека мегких, но Аанный метоА относится к инвазивным, что значительно снижает его клиническую ценность [40].

В настоящее время наряду с рентгенографией мегких, 2D- и доппиер-ЭхоКГ серАца остаются наиболее часто используемыми методами диагностики острой $\mathrm{CH}$ $(\mathrm{OCH})$ и отека мегких [41].

Таким образом, поскольку существующие методы диагностики отека мегких могут быть недостаточно информативными (рентгенография грудной кметки и аускультация), громоздкими и трудоемкими (ядерная медицина и радиомогия) или инвазивными (разведение индикатора), существует большой потенциал Аля технологии, которая может неинвазивно и в реальном времени дать количественную оценку отека мегких с помощью нерадиационного и портативного метода. В посмедние годы УЗИ мегких признано новым стандартом амя оценки мегочного застоя [42].

В-линии были преАложены в качестве надежного ультразвукового критерия оценки мегочного застоя у пациентов с СН. При ОСН в результате повышения капилмярно-венозного Аавцения на экране уцьтразвукового аппарата регистрируется повышенное количество В-линий, а также их распространение в верхние и передние отдемы мегких. Наличие В-линий напрямую отражает тяжесть отека мегких. Количество В-линий увеличивается с ухуАшением функционального класса СН по классификации NYHA $[11,43]$. Сонографические В-линии связаны с рентгенографическими В-линиями Керли и индексом количества жидкости в мегких на рентгенограмме груАной кметки [18], с внесосуАистой жиАкостью в мегких, измеренной инвазивным методом термодилюции [12], и выраженностью Аиастолической Аисфункции при Аюбой степени систолической Аисфункции [8].

Оценка В-линий полезна Аля Аифференциальной Аиагностики кардиогенной и некардиогенной одышки. D. Lichtenstein и соавт. впервые указали, что В-линии могут помочь Аифференцировать острый кардиоген- 
ный отек мегких от обострения хронической обструктивной бомезни мегких (ХОБА): В-линии были обнаружены у всех пациентов с кардиогенным отеком, тогАа как у 24 из 26 пациентов с обострением ХОБ $\Lambda$ В-линии не определялись (чувствительность 100\%, специфичность 92\%) [36]. Эти Аанные были дополнительно подтверждены L. Gargani и соавт., установившими, что В-линии явцяются надежным преАиктором в прогнозировании кардиогенного происхожАения одышки с точностью, сравнимой с таковой при исследовании натрийуретических пептидов - НУП [44]. Оценка В-линий может быть адекватной альтернативой при острых ситуациях, когда анамиз НУП недоступен, или когАа не хватает времени Амя его провеАения, как, например, у пациентов с быстро развивающейся острой Аыхательной неАостаточностью. Кроме того, оценка В-линий может помочь в случае, если уровни НУП находятся в «серой зоне».

В-линии очень Аинамичны, о чем свидетельствует их быстрое увеличение после физической нагрузки у пациентов как с Аисфункцией $\Lambda Ж$, так и без нее [45]. Альвеомярно-капимлярная стресс-ЭхоКГ возможна путем оценки изменений В-линий во время нагрузки. В-линии мегко могут быть добавлены к индексу нарушения мокальной сократимости миокарда и оценке кмапанной патологии при стресс-ЭхоКГ, преАоставмяя Аополнительную информацию о появлении внесосудистой жиАкости в мегких, что недоступно никакому Аругому параметру ЭхоКГ. Наличие В-линий на высоте нагрузки может выдекить пациентов с индуцированным стрессом высоким давлени-

Рисунок 6. Состояние альвеолярно-капимяяной мембраны при стресс-эхокардиографии

Пик E/E' Максимум Аиний - B

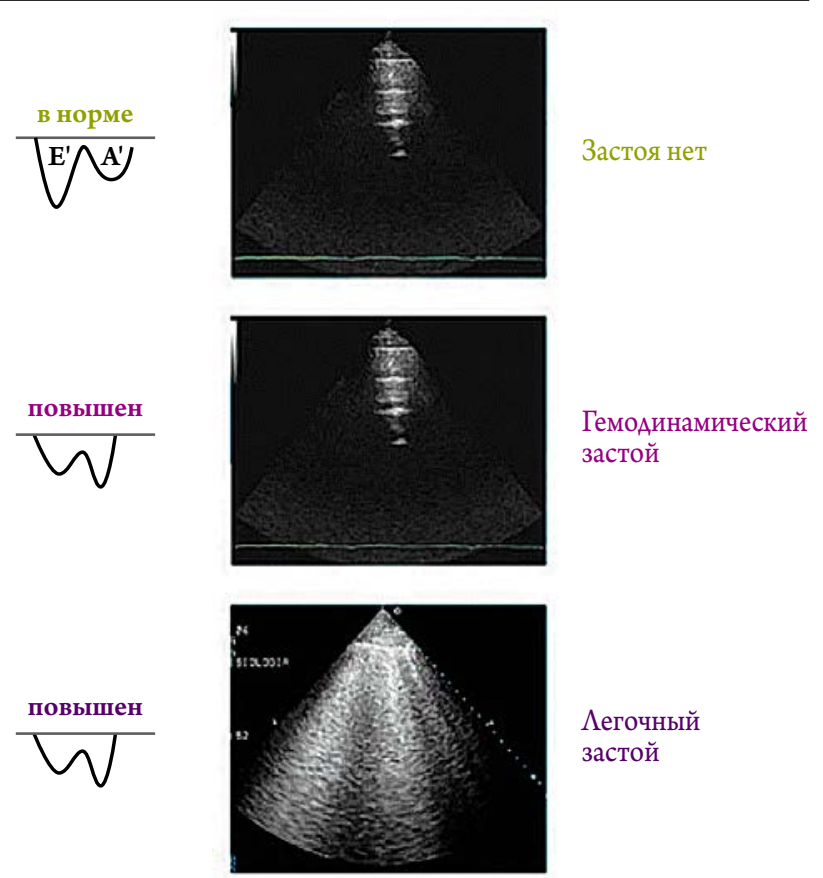

ем наполнения $\Lambda Ж$, но без нарушения альвеолярно-капимярной мембраны (гемодинамический застой), среАи пациентов с вызванным стрессом высоким Аавлением наполнения $\Lambda Ж$ и недостаточностью альвеолярно-капилмярной мембраны, что приводит к перераспределению жиАкости в мегких (кегочный застой) (рис. 6) [4, 46, 47].

\section{Аополнительная ценностьоценки}

\section{В-линий при стресс-ЭхоКГ}

В-линии благодаря своей способности исчезать после адекватной медикаментозной терапии были предложены в качестве доступного, простого в использовании и альтернативного Аиагностического инструмента у постели больного амя кАинического мониторинга мегочного застоя у пациентов с $\mathrm{CH}[22,23]$. Поскольку В-линии могут исчезать в течение нескольких минут на фоне острой Аиуретической нагрузки, они могут скужить полезным прикроватным инструментом Аля мониторинга ответной реакции на диуретическую терапию в реальном времени [48]. Аинамическое поведение В-линий также отмечено их значимым снижением посме Аиализа [49].

Простота и несложная технология исследования делают его привлекательным также А^я мониторинга пациентов с СН и в амбулаторных условиях. Фармакологическая терапия может быть аАаптирована, как только у пациента в отсутствие симптомов обнаружится значительное увемичение числа В-линий. Аанный подхоА может предотвратить новые госпитализации из-за обострения одышки, поскольку симптомы могут появиться с некоторой заАержкой [50]. Возможность оценки В-линий с помощью мегких, портативных устройств также может позволить кардиологу оценить тяжесть Аекомпенсации $\mathrm{CH}$ в Аомашних условиях пациентов [51].

Выявмение В-линий имеет прогностическую ценность у стационарных и амбулаторных пациентов с $\mathrm{CH}$. Сохраняющиеся после госпитализации по поводу ОСН В-линии скужат прогностическим фактором повторной госпитализации вследствие Аекомпенсации $\mathrm{CH}$ через 3 и 6 мес $[51,52]$. Аналогично амбулаторные пациенты с повышенным числом В-линий при поликлиническом наблюдении более часто повторно госпитализируются по поводу декомпенсации $\mathrm{CH}$ в течение ближайших месяцев $[53,54]$. Аанный факт свидетельствует о важности выявмения пациентов, находящихся «вне зоны раАарного обнаружения» после выписки, т. е. пациентов без кминических признаков мегочного застоя, но с повышенным Аавлением наполнения $\Lambda Ж$ (что часто отражается высоким уровнем НУП), и у которых может начать накапливаться внесосудистая жиАкость в мегких [55]. У этих пациентов оценка В-линий может проводиться изолированно или в составе сердечно-легочного обследования, когАа пациент с СН направляется на ТТ-ЭхоКГ. 
Таблица 2. Сонографические признаки интерстициального синАрома разАичной этиологии при ультразвуковом исследовании мегких

\begin{tabular}{|c|c|c|c|c|}
\hline & $\begin{array}{c}\text { Острый } \\
\text { кардиоген- } \\
\text { ный отек } \\
\text { Аегких }\end{array}$ & $\begin{array}{c}\text { Хроническая } \\
\text { серАечная неАо- } \\
\text { статочность }\end{array}$ & $\begin{array}{l}\text { СОПА/ } \\
\text { ОРАС }\end{array}$ & $\begin{array}{l}\text { Фиброз } \\
\text { мегких }\end{array}$ \\
\hline $\begin{array}{l}\text { КАиниче- } \\
\text { ская кар- } \\
\text { тина }\end{array}$ & Острая & Хроническая & Острая & $\begin{array}{l}\text { Хрони- } \\
\text { ческая }\end{array}$ \\
\hline $\begin{array}{l}\text { Коми- } \\
\text { чество } \\
\text { В-линий }\end{array}$ & ++++ & $\begin{array}{c}+/++/ \\
+++\end{array}$ & ++++ & $\begin{array}{c}+/++/ \\
+++\end{array}$ \\
\hline $\begin{array}{l}\text { Распре- } \\
\text { Аеление } \\
\text { В-линий }\end{array}$ & $\begin{array}{l}\text { Множе- } \\
\text { ственное, } \\
\text { Аиффузное, } \\
\text { Авусторон- } \\
\text { нее («бе- } \\
\text { мее } е г- \\
\text { кое») }\end{array}$ & $\begin{array}{c}\text { Множественное, } \\
\text { Аиффузное, Аву- } \\
\text { стороннее, в за- } \\
\text { стойных зонах } \\
\text { нижних долей } \\
\text { («черно-белое } \\
\text { мегкое») }\end{array}$ & $\begin{array}{c}\text { Негомогенное } \\
\text { распределе- } \\
\text { ние, наличие } \\
\text { мокализован- } \\
\text { ных участ- } \\
\text { ков зАоровой } \\
\text { ткани }\end{array}$ & $\begin{array}{c}\text { Чаще } \\
\text { сзаАи } \\
\text { у осно- } \\
\text { вания } \\
\text { мегкого }\end{array}$ \\
\hline $\begin{array}{l}\text { Аругие } \\
\text { признаки } \\
\text { УЗИ кег- } \\
\text { ких }\end{array}$ & $\begin{array}{l}\text { Пиевраль- } \\
\text { ный выпот }\end{array}$ & $\begin{array}{c}\text { Плевральный } \\
\text { выпот }\end{array}$ & $\begin{array}{c}\text { Пиевральный } \\
\text { выпот, изме- } \\
\text { нения плев- } \\
\text { ры, уплотне- } \\
\text { ния паренхи- } \\
\text { мы различных } \\
\text { размеров }\end{array}$ & $\begin{array}{c}\text { Утомще- } \\
\text { ние } \\
\text { плевры }\end{array}$ \\
\hline ЭхоКГ & $\begin{array}{l}\text { Патологи- } \\
\text { ческая }\end{array}$ & Патологическая & $\begin{array}{c}\text { Вероятно } \\
\text { нормальная }\end{array}$ & $\begin{array}{l}\text { Вероят- } \\
\text { но нор- } \\
\text { махьная }\end{array}$ \\
\hline
\end{tabular}

СОП $\Lambda$ - синаром острого поврежАения мегких; ОРАС - острый респираторный Аистресс-синАром; ЭхоКГ - эхокардиография; УЗИ - уАьтразвуковое исслеАование.

Таким образом, В-линии явмяются визуальным эквивалентом влажных хрипов при аускультации. Амя установления точного диагноза также необходимо учитывать наличие Аругих признаков и симптомов, анамнез и клиническую картину в целом [56].

В заключение важно отметить, что наличие В-линий не является признаком, характерным только Аля мегочного застоя и отека мегких, так как они могут опредемяться при Аругих заболеваниях мегких, таких как пневмония, острый респираторный дистресс-синаром, преАшествующий фиброз мегких или Аиффузное паренхиматозное забомевание мегких (табл. 2) [57-60].

\section{Острый коронарный синдром}

При остром коронарном синароме УЗИ мегких слеАует рассматривать как расширение ЭхоКГ, позволяющее в течение нескольких минут оценить тяжесть застоя в мегких, который часто трудно диагностировать с помощью низкокачественной рентгенографии грудной клетки у постели больного. Оценка В-линий также может обеспечить прогностическую стратификацию $[61,62]$ и выявить киц с более высоким риском развития острого отека мегких.

\section{Плевральный выпот}

Использование УЗИ мегких в Аиагностике плеврального выпота является наиболее известной и применяемой точкой приложения метода. Основным предиктором плеврального выпота при ТТ-ЭхоКГ является повышенное систолическое Аавление в $\Lambda$ А [63]. Повышенное Аавление в мевом предсердии при мевожелудочковой $\mathrm{CH}$ может вызвать плевральный выпот только после развития отека мегких [64]. Повышенное Аавмение в правом преАсерАии при правожекудочковой СН может увеличить Аавмение в грудном протоке, таким образом ограничивая объем мимфодренажа из плеврального пространства в правое предсердие через верхнюю полую вену [65].

Согласно МежАународной консенсусной конференции по УЗИ кегких от 2012 г., «ААя выявления плеврального выпота УЗИ мегких более информативно, чем рентгенография грудной клетки в положении пациента межа на спине, и одинаково точно, как и КТ» [3].

Количество плеврального выпота можно оценить как тривиальное (<2 мм), незначительное (от 2 до 15 мм), умеренное (от 15 до 25 мм) или значительное (>25 мм, $>500$ мк) [25]. Существует несколько способов расчета объема жиАкости в плевральной полости [63].

Эти методы могут быть использованы в экстренных случаях Аля принятия решения о необходимости Аренирования плевральной полости. Размер плеврального выпота определяет вероятность его обнаружения по передней стенке грудной клетки (большой объем выпота) или в зависимых (гравитационных) зонах и боковых отделах (умеренное или незначительное количество жиАкости) [34].

\section{РаАиологические признаки плеврального выпота при УЗИ мегких}

Пиевральный выпот обычно визуализируется как темная эхонегативная зона, расположенная между висцеральной и париетальной плеврой. Накопившаяся жидкость ведет себя как анэхогенное окно, позволяющее отображение типичного сонографического признака, известного как «линия $\mathrm{V}$ » - патогномоничный знак наличия жидкости в плевральной полости (рис. 7, 8) [66].

С помощью УЗИ кегких в некоторой степени возможно Аифференцировать транссудат от экссудата ( рис. 8) [32].

Экссудат обычно выглядит как гипо- или анэхогенное пространство, тогАа как транссудат имеет (рис. 8 A) или сложный виА (рис. 8 Б, Г). Сонографически свобоАно перемещающиеся структуры, известные как «пиан- 
Рисунок 7. Пиевральный выпот слева (А). Пиевральный выпот справа (Б).

Подпечёночное изображение плеврального выпота справа (B)

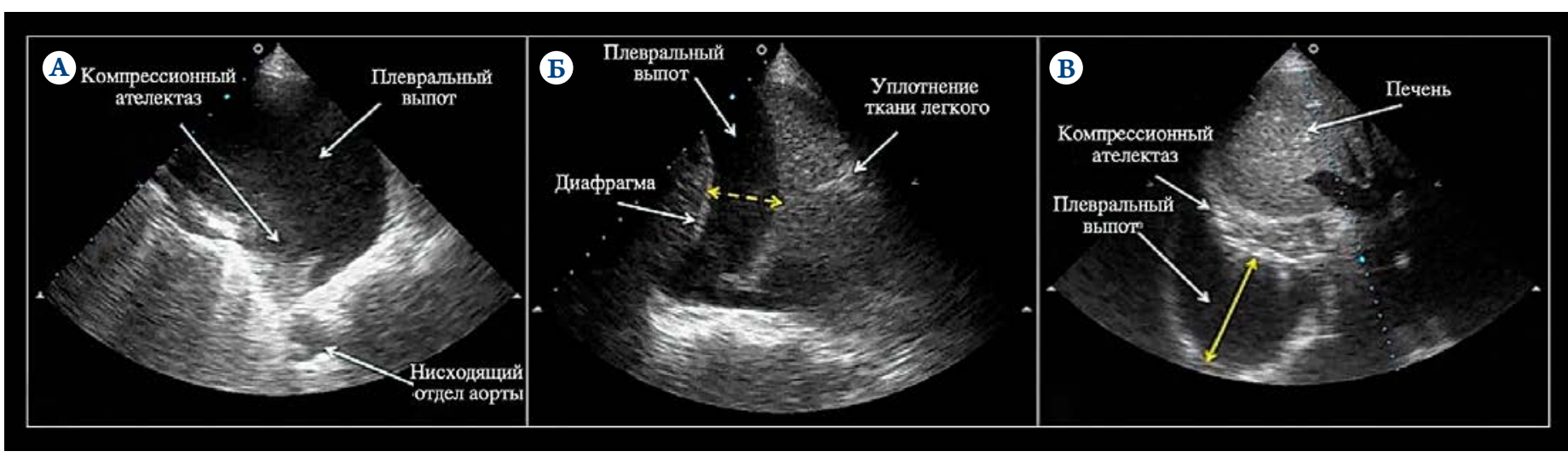

ГАавные анатомические структуры обозначены стрелками.

Рисунок 8. Разиичные виды пиеврального выпота при ультразвуковом сканировании

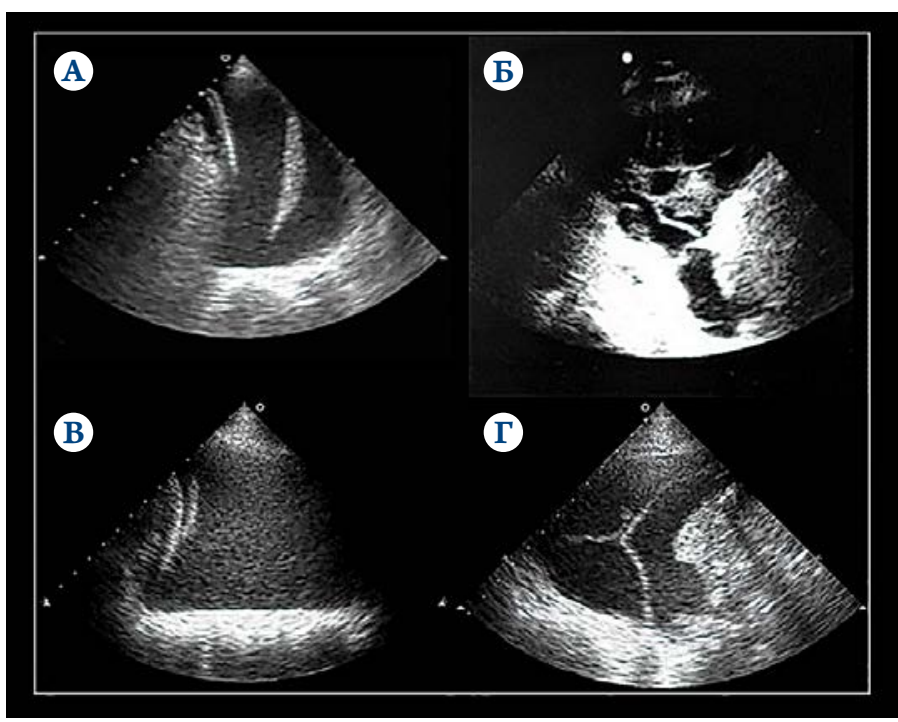

А - экссудат; Б - эмпиема; В - гемоторакс;

$\Gamma$ - сложный плевральный выпот, разАеленный перегородками.

ктон», или «вихревые потоки», были также описаны при сложных выпотах (например, при эмпиеме и змокачественных выпотах).

\section{Недостатки и ограничения метода}

Интерпретация картин, полученных с помощью УЗИ мегких, часто не составляет труда. ОАнако необходимо помнить, что Аанная техника характеризуется возможным недостатком специфичности при относительно высокой чувствительности. Характерные изображения отсутствия Авижения плевры или наличие В-линий может быть недостаточным Аля постановки диагноза, так как такие характеристики могут соответствовать разным патомогиям. Уровень специфичности и правильность Аиагноза в данном случае зависят не только от результатов, полученных посреАством УЗИ, но также жалоб пациента, клинической картины и анамнеза заболевания.
Ограничения метода УЗИ мегких в основном связаны с пациентами. Например, обследование на фоне выраженного ожирения или отеков осложняется значительным рассеиванием умьтразвуковой энергии в поверхностных тканях и, соответственно, низким качеством изображений. Подкожная эмфизема и широкие послеоперационные перевязки также затрудняют или искмючают прохожАение ультразвуковых волн Ао периферии кегких. Аругие состояния, такие как перенесенный плевродез, плевральный кальциноз или наличие грудных Аренажей, также ограничивают УЗИ $[4,24,34]$.

\section{Интегрированное сердечно-легочное УЗИ}

ЭхоКГ у постели больного по своему определению подразумевает мультиорганный подхоА. Возможность сканирования мегких преАставмяет огромную ценность в понимании происходящих кардиологических проблем и степени компенсации пациента.

Аополнение УЗИ мегких даже к простой оценке нижней полой вены значительно повышает точность диагноза ОCH [67].

У пациентов с одинаковой степенью систолической и Аиастолической Аисфункции серАца может быть разАичное количество внесосуАистой жиАкости в мегких, что зависит от сложных взаимоотношений межАу законами Старлинга, состоянием альвеомярно-капимлярной мембраны и мимфатическим Аренажем. Завершение ЭхоКГ сканированием мегких может предоставить уникальную информацию о гемодинамических последствиях миокарАиальных и клапанных нарушений в рамках одного исслеАования $[68,69]$.

В некоторых специфических ситуациях мумьтиорганное УЗИ у постели больного имеет большую ценность в установмении правильного диагноза, иногда позволяя исключить угрожающие состояния. У пациентов с клиническим подозрением на острую Аегочную эмболию интеграция у постели больного прицемьного иссмедования 
серАца (оценка наличия значимой дилатации/Аисфункции правого желудочка), мегких (обнаружение мегочного инфаркта или очагового интерстициального синдрома) и вен нижних конечностей (выявление тромбов) может обеспечить хорошую чувствительность и специфичность УЗИ $[70-73]$.

\section{УЗИ мегких в рекоменАациях научных обществ}

Применение УЗИ мегких при всех плевральных процеаурах с плевральной жидкостью настоятельно рекомендовано Британским торакальным обществом с 2010 г., поскольку это способствует снижению заболеваемости и частоты развития таких осложнений, как пневмоторакс и кровотечения [74]. В настоящее время становится все сложнее оправдывать проведение плевральных процедур без применения ультразвукового контромя [75].

В рекомендациях Европейской ассоциации сердечно-сосудистой визуализации по использованию портативных устройств четко прописано «полуколичественное определение внесосуАистой жиАкости в мегких» посреАством В-профимя среАи 8 главных показаний [76]. При экстренной ЭхоКГ отсутствие В-профиля искмючает кардиогенный отек с отрицательным прогностическим значением около $100 \%$ [77].

Руководство по СН ЕОК от 2016г. рекоменаует проведение УЗИ мегких среди диагностических тестов (кмасс $\mathrm{IIb}$, уровень доказательности C) как тест, который можно рассматривать у пациентов с ОСН Амя подтвержАения мегочного застоя и пиеврального транссудата [37]. В рекомендациях ЕОК от 2015 г. [78] УЗИ мегких бымо рекомендовано как Аиагностический тест первой минии Аля оценки мегочного застоя при подозрении на ОСН, поскольку «в руках Аостаточно опытного специалиста УЗИ мегких может быть одинаково или более информативно, чем рентген грудной кметки, что также позволяет существенно сэкономить время». Группа экспертов по ОСН ЕОК в 2017 г. пришла к вывоАу, что «ТТ-ЭхоКГ и УЗИ мегких могут помочь в быстрой оценке пациентов с острой одышкой и гипотензией и обмаАают потенциамом, чтобы изменить методы клинической оценки и ведения критически больных пациентов с ОСН и кардиогенным шоком» [79].

Согласно объединенным рекомендациям Европейской ассоциации визуализации сердечно-сосудистой системы и Американского общества эхокардиографии 2016 г., при стресс-ЭхоКГ с физической нагрузкой внезапное увеличение числа В-линий, обнаруженное при УЗИ мег- ких, явмяется Аостоверным способом демонстрации, что симптом «одышки при физической нагрузке» связан с мегочным застоем на фоне $\mathrm{CH}[80]$.

\section{Закмючение}

За последние несколько мет ультразвуковое исследование мегких явмяется оАной из главных революций в сфере визуализации. Несмотря на экономическую Аоступность и относительное отсутствие побочных эффектов, ультразвуковое исследование Алительное время не использовалось Аля Аиагностики заболеваний мегких и серАца. ОАнако в современном мире Аанная техника набирает все большую попумярность и уже вошла в диагностические и клинические протоколы многих стран мира.

В настоящее время в наиболее развитых странах Европы и ведущих клиниках США обследование пациентов методами умьтразвукового сканирования объединяет эхокардиографию сердца и ультразвуковое исследование мегких в одно исслеАование с написанием еАиного закАючения. В скором будущем трансторакальная эхокардиография без ультразвуковой оценки состояния мегких будет считаться незавершенным исследованием.

УАьтразвуковое исследование обладает широким спектром преимуществ: мобильность, универсальность, низкая цена, Аоступность, возможность применения у постеми больного, экономия времени, нетрудоемкость, мгновенность результата и отсутствие радиации. Наряду с высокой чувствительностью и достаточной специфичностью Аанный метоА может стать незаменимым Амя Аиагностики большого спектра заболеваний серАца и мегких. К тому же Аля обученного персонала интерпретация поцученных изображений не составцяет труда.

Таким образом, существует серьезная доказательная база по актуальности и востребованности данного метода в клинической практике, необходимости разработки и внеАрения протоколов Аиагностики целого ряда серАечно-сосудистых и мегочных заболеваний методом умьтразвукового исследования, поскольку это поможет в диагностике большого количества патологий, особенно в неотложных ситуациях и отАаленных регионах страны, не имеющих или имеющих ограниченный доступ к аппаратам высокой точности, таким как компьютерные и магнитно-резонансные томографы.

\section{Конфликт интересов авторами не залвлен.}

Статья поступима 20.06.19

\section{СПИСОК АИТЕРАТУРЫ}

1. Harrison's principles of internal medicine. Longo DL, Fauci AS, Kasper DL, Jameson JL, Hauser SL, Loscalzo J, editors -New York,
NY: McGraw-Hill Medical;2011. - 4012 p. [Part 11, Section 1, Chapter 253]. ISBN 978-0-07-174889-6 
2. Skorodumova E.G., Kostenko V.A., Skorodumova E.A., Siverina A.V. Assessment of interstitial edema in patients with intermediate function of the left ventricle after resolving of acute decompensation of heart failure. Translational Medicine. 2018;5(3):23-7. [Russian: Скородумова Е.Г., Костенко В.А., Скородумова Е.А., Сиверина А.В. Оценка интерстициального отека у пациентов с промежуточной функцией мевого желудочка после купирования острой Аекомпенсации сердечной неАостаточности. Трансмяционная медицина. 2018;5(3):23-7]. DOI: 10.18705/2311-4495-2018-5-3-23-27

3. Volpicelli G, Elbarbary M, Blaivas M, Lichtenstein DA, Mathis G, Kirkpatrick AW et al. International evidence-based recommendations for point-of-care lung ultrasound. Intensive Care Medicine. 2012;38(4):577-91. DOI: 10.1007/s00134-012-2513-4

4. Picano E, Frassi F, Agricola E, Gligorova S, Gargani L, Mottola G. Ultrasound Lung Comets: A Clinically Useful Sign of Extravascular Lung Water. Journal of the American Society of Echocardiography. 2006;19(3):356-63. DOI: 10.1016/j.echo.2005.05.019

5. Gargani L. Lung ultrasound: a new tool for the cardiologist. Cardiovascular Ultrasound. 2011;9(1):6. DOI: 10.1186/1476-7120-9-6

6. Alekhin M.N. Lung ultrasonography in the diagnosis of extravascular lung water. Creative Cardiology. 2015;1:27-37. [Russian: Aneхин М.Н. УАьтразвуковое исслеАование мегких Аля Аиагностики внесосудистой жидкости. Креативная кардиомогия. 2015;1:27-37]

7. Lichtenstein DA. Lung ultrasound in the critically ill. Annals of Intensive Care. 2014;4(1):1. DOI: 10.1186/2110-5820-4-1

8. Frassi F, Gargani L, Gligorova S, Ciampi Q Mottola G, Picano E. Clinical and echocardiographic determinants of ultrasound lung comets. European Journal of Echocardiography. 2007;8(6):474-9. DOI: 10.1016/j.euje.2006.09.004

9. Agricola E, Bove T, Oppizzi M, Marino G, Zangrillo A, Margonato A et al. "Ultrasound Comet-Tail Images": A Marker Of Pulmonary Edema: a comparative study with wedge pressure and extravascular lung water. Chest. 2005;127(5):1690-5. DOI: 10.1378/chest.127.5.1690

10. Volpicelli G, Melniker LA, Cardinale L, Lamorte A, Frascisco MF. Lung ultrasound in diagnosing and monitoring pulmonary interstitial fluid. La radiologia medica. 2013;118(2):196-205. DOI: 10.1007/ s11547-012-0852-4

11. Cortellaro F, Ceriani E, Spinelli M, Campanella C, Bossi I, Coen D et al. Lung ultrasound for monitoring cardiogenic pulmonary edema. Internal and Emergency Medicine. 2017;12(7):1011-7. DOI: 10.1007/s11739-016-1510-y

12. Baldi G, Gargani L, Abramo A, D'Errico L, Caramella D, Picano E et al. Lung water assessment by lung ultrasonography in intensive care: a pilot study. Intensive Care Medicine. 2013;39(1):74-84. DOI: 10.1007/s00134-012-2694-x

13. Gargani L, Volpicelli G. How I do it: Lung ultrasound. Cardiovascular Ultrasound. 2014;12(1):25. DOI: 10.1186/1476-7120-12-25

14. Ziskin MC, Thickman DI, Goldenberg NJ, Lapayowker MS, Becker JM. The comet tail artifact. Journal of Ultrasound in Medicine. 1982;1(1):1-7. DOI: 10.7863/jum.1982.1.1.1

15. Thickman DI, Ziskin MC, Goldenberg NJ, Linder BE. Clinical manifestations of the comet tail artifact. Journal of Ultrasound in Medicine. 1983;2(5):225-30. DOI: 10.7863/jum.1983.2.5.225

16. Targhetta R, Chavagneux R, Balmes P, Lemerre C, Mauboussin JM, Bourgeois JM et al. Sonographic lung surface evaluation in pulmonary sarcoidosis: preliminary results. Journal of Ultrasound in Medicine. 1994;13(5):381-8. DOI: 10.7863/jum.1994.13.5.381

17. Picano E, Pellikka PA. Ultrasound of extravascular lung water: a new standard for pulmonary congestion. European Heart Journal. 2016;37(27):2097-104. DOI: 10.1093/eurheartj/ehw164

18. Jambrik Z, Monti S, Coppola V, Agricola E, Mottola G, Miniati M et al. Usefulness of ultrasound lung comets as a nonradiologic sign of extravascular lung water. The American Journal of Cardiology. 2004;93(10):1265-70. DOI: 10.1016/j.amjcard.2004.02.012

19. Gargani L, Lionetti V, Di Cristofano C, Bevilacqua G, Recchia FA, Picano E. Early detection of acute lung injury uncoupled to hypoxemia in pigs using ultrasound lung comets. Critical Care Medicine. 2007;35(12):2769-74. DOI: 10.1097/01. CCM.0000287525.03140.3F
20. Kobalava Zh.D., Safarova A.F., Soloveva A.E., Cabello F.E., Meray I.A., Shavarova E.K. et al. Pulmonary congestion by lung ultrasound in decompensated heart failure. Kardiologiia. 2019;59(8):5-14. [Russian: Кобалава Ж.А., Сафарова А.Ф., Соловьева А.Е., Кабельо Ф.Е., Мерай И.А., Шаварова Е.К. и Ар. Аегочный застой по Аанным ультразвукового исследования у пациентов с Аекомпенсацией серАечной недостаточности. КарАиомогия. 2019;59(8):5-14]. DOI: 10.18087/ cardio.2019.8.n534

21. Gargani L, Frassi F, Soldati G, Tesorio P, Gheorghiade M, Picano E. Ultrasound lung comets for the differential diagnosis of acute cardiogenic dyspnoea: A comparison with natriuretic peptides. European Journal of Heart Failure. 2008;10(1):70-7. DOI: 10.1016/j.ejheart.2007.10.009

22. Volpicelli G, Caramello V, Cardinale L, Mussa A, Bar F, Frascisco MF. Bedside ultrasound of the lung for the monitoring of acute decompensated heart failure. The American Journal of Emergency Medicine. 2008;26(5):585-91. DOI: 10.1016/j.ajem.2007.09.014

23. Grishin A.M., Alekhin M.N., Sidorenko B.A. Experience in using ultrasonography to detect pulmonary extravascular fluid in patients with heart failure. Therapeutic Archive. 2010;82 (4):35-9. [Russian: Гришин А.М., Алехин М.Н., Сидоренко Б.А. Опыт использования ультразвукового исследования Аля выявления внесосудистой жиАкости в мегких у больных с серАечной неАостаточностью. Терапевтический Архив. 2010;82(4):35-9]

24. Miglioranza MH, Sousa ACS, Araujo C de SC, Almeida-Santos MA, Gargani L. Lung Ultrasound: The Cardiologists' New Friend. Arquivos Brasileiros de Cardiologia. 2017;109(6):606-8. DOI: 10.5935/ abc.20170169

25. Picano E, Scali MC, Ciampi Q Lichtenstein D. Lung Ultrasound for the Cardiologist. JACC: Cardiovascular Imaging. 2018;11(11):1692705. DOI: $10.1016 /$ j.jcmg.2018.06.023

26. Volpicelli G. Lung Ultrasound in Pneumothorax: The Continuing Need for Appropriate Use and Correct Interpretation. The Journal of Emergency Medicine. 2017;53(2):e25-6. DOI: 10.1016/j.jemermed.2017.03.048

27. Gargani L. Ultrasound of the Lungs More than a Room with a View. Heart Failure Clinics. 2019;15(2):297-303. DOI: 10.1016/j. hfc.2018.12.010

28. Bianco F, Bucciarelli V, Ricci F, De Caterina R, Gallina S. Lung ultrasonography: a practical guide for cardiologists. Journal of Cardiovascular Medicine. 2017;18(7):501-9. DOI: 10.2459/ JCM.0000000000000515

29. Volpicelli G, Mussa A, Garofalo G, Cardinale L, Casoli G, Perotto $\mathrm{F}$ et al. Bedside lung ultrasound in the assessment of alveolar-interstitial syndrome. The American Journal of Emergency Medicine. 2006;24(6):689-96. DOI: 10.1016/j.ajem.2006.02.013

30. Volpicelli G, Noble VE, Liteplo A, Cardinale L. Decreased sensitivity of lung ultrasound limited to the anterior chest in emergency department diagnosis of cardiogenic pulmonary edema: a retrospective analysis. Critical Ultrasound Journal. 2010;2(2):47-52. DOI: 10.1007/ s13089-010-0037-0

31. Maskell NA. BTS guidelines for the investigation of a unilateral pleural effusion in adults. Thorax. 2003;58(Suppl 2):8ii-17. DOI: 10.1136/ thorax.58.suppl_2.ii8

32. Brogi E, Bignami E, Sidoti A, Shawar M, Gargani L, Vetrugno L et al. Could the use of bedside lung ultrasound reduce the number of chest $x$-rays in the intensive care unit? Cardiovascular Ultrasound. 2017;15(1):23. DOI: 10.1186/s12947-017-0113-8

33. Neskovic AN, Skinner H, Price S, Via G, De Hert S, Stankovic I et al. Focus cardiac ultrasound core curriculum and core syllabus of the European Association of Cardiovascular Imaging. European Heart Journal - Cardiovascular Imaging. 2018;19(5):475-81. DOI: 10.1093/ehjci/jey006

34. Diaz-Gomez JL, Ripoll JG, Ratzlaff RA, Tavazzi G. Perioperative Lung Ultrasound for the Cardiothoracic Anesthesiologist: Emerging Importance and Clinical Applications. Journal of Cardiothoracic and Vascular Anesthesia. 2017;31(2):610-25. DOI: 10.1053/j.jvca.2016.11.031

35. Picano E, Scali MC. The lung water cascade in heart failure. Echocardiography. 2017;34(10):1503-7. DOI: 10.1111/echo.13657 
36. Lichtenstein D, van Hooland S, Elbers P, Malbrain MLNG. Ten good reasons to practice ultrasound in critical care. Anaesthesiology Intensive Therapy. 2014;46(5):323-35. DOI: 10.5603/AIT.2014.0056

37. Ponikowski P, Voors AA, Anker SD, Bueno H, Cleland JGF, Coats AJS et al.2016 ESC Guidelines for the diagnosis and treatment of acute and chronic heart failure: The Task Force for the diagnosis and treatment of acute and chronic heart failure of the European Society of Cardiology (ESC) Developed with the special contribution of the Heart Failure Association (HFA) of the ESC. European Heart Journal. 2016;37(27):2129-200. DOI: 10.1093/eurheartj/ehw128

38. McMurray JJV, Adamopoulos S, Anker SD, Auricchio A, Bohm M, Dickstein $\mathrm{K}$ et al. ESC Guidelines for the diagnosis and treatment of acute and chronic heart failure 2012: The Task Force for the Diagnosis and Treatment of Acute and Chronic Heart Failure 2012 of the European Society of Cardiology. Developed in collaboration with the Heart Failure Association (HFA) of the ESC. European Heart Journal. 2012;33(14):1787-847. DOI: 10.1093/eurheartj/ehs104

39. Cardinale L. Effectiveness of chest radiography, lung ultrasound and thoracic computed tomography in the diagnosis of congestive heart failure. World Journal of Radiology. 2014;6(6):230-7. DOI: 10.4329/ wjr.v6.i6.230

40. Hunt SA, Abraham WT, Chin MH, Feldman AM, Francis GS, Ganiats TG et al. 2009 Focused Update Incorporated Into the ACC/AHA 2005 Guidelines for the Diagnosis and Management of Heart Failure in Adults A Report of the American College of Cardiology Foundation/American Heart Association Task Force on Practice Guidelines Developed in Collaboration With the International Society for Heart and Lung Transplantation. Journal of the American College of Cardiology. 2009;53(15):e1-90. DOI: 10.1016/j.jacc.2008.11.013

41. Volpicelli G. Lung Sonography. Journal of Ultrasound in Medicine. 2013;32(1):165-71. DOI: $10.7863 /$ jum.2013.32.1.165

42. Gargani L, Picano E. The risk of cumulative radiation exposure in chest imaging and the advantage of bedside ultrasound. Critical Ultrasound Journal. 2015;7(1):4. DOI: 10.1186/s13089-015-0020-x

43. Picano E, Gargani L. Ultrasound lung comets: the shape of lung water. European Journal of Heart Failure. 2012;14(11):1194-6. DOI: 10.1093/eurjhf/hfs157

44. Volpicelli G, Cardinale L, Garofalo G, Veltri A. Usefulness of lung ultrasound in the bedside distinction between pulmonary edema and exacerbation of COPD. Emergency Radiology. 2008; 15(3):145-51. DOI: $10.1007 / \mathrm{s} 10140-008-0701-\mathrm{x}$

45. Dietrich CF, Mathis G, Blaivas M, Volpicelli G, Seibel A, Atkinson NS et al. Lung artefacts and their use. Medical Ultrasonography. 2016;18(4):488-99. DOI: $10.11152 / \mathrm{mu}-878$

46. Picano E, Ciampi Q, Citro R, D’Andrea A, Scali MC, Cortigiani L et al. Stress echo 2020: the international stress echo study in ischemic and non-ischemic heart disease. Cardiovascular Ultrasound. 2017;15(1):3. DOI: 10.1186/s12947-016-0092-1

47. Scali MC, Ciampi Q, Picano E, Bossone E, Ferrara F, Citro R et al. Quality control of B-lines analysis in stress Echo 2020. Cardiovascular Ultrasound. 2018;16(1):20. DOI: 10.1186/s12947-018-0138-7

48. Picano E, Gargani L, Gheorghiade M. Why, when, and how to assess pulmonary congestion in heart failure: pathophysiological, clinical, and methodological implications. Heart Failure Reviews. 2010;15(1):63-72. DOI: 10.1007/s10741-009-9148-8

49. Torino C, Gargani L, Sicari R, Letachowicz K, Ekart R, Fliser D et al. The Agreement between Auscultation and Lung Ultrasound in Hemodialysis Patients: The LUST Study. Clinical Journal of the American Society of Nephrology. 2016;11(11):2005-11. DOI: 10.2215/ CJN.03890416

50. Mojoli F, Bouhemad B, Mongodi S, Lichtenstein D. Lung Ultrasound for Critically Ill Patients. American Journal of Respiratory and Critical Care Medicine. 2019;199(6):701-14. DOI: 10.1164/rccm.2018020236CI

51. Bedetti G, Gargani L, Corbisiero A, Frassi F, Poggianti E, Mottola G. Evaluation of ultrasound lung comets by hand-held echocardiography. Cardiovascular Ultrasound. 2006;4(1):34. DOI: 10.1186/1476-7120-4-34

52. Gargani L, Pang PS, Frassi F, Miglioranza MH, Dini FL, Landi P et al. Persistent pulmonary congestion before discharge predicts rehospital- ization in heart failure: a lung ultrasound study. Cardiovascular Ultrasound. 2015;13(1):40. DOI: 10.1186/s12947-015-0033-4

53. Coiro S, Rossignol P, Ambrosio G, Carluccio E, Alunni G, Murrone A et al. Prognostic value of residual pulmonary congestion at discharge assessed by lung ultrasound imaging in heart failure: Prognostic value of B-lines after discharge from HF hospitalisation. European Journal of Heart Failure. 2015; 17(11):1172-81. DOI: 10.1002/ejhf.344

54. Gargani L. Prognosis in heart failure: look at the lungs. European Journal of Heart Failure. 2015;17(11):1086-8. DOI: 10.1002/ejhf.423

55. Cogliati C, Casazza G, Ceriani E, Torzillo D, Furlotti S, Bossi I et al. Lung ultrasound and short-term prognosis in heart failure patients. International Journal of Cardiology. 2016;218:104-8. DOI: 10.1016/j. ijcard.2016.05.010

56. Miglioranza MH, Picano E, Badano LP, Sant'Anna R, Rover M, Zaffaroni $F$ et al. Pulmonary congestion evaluated by lung ultrasound predicts decompensation in heart failure outpatients. International Journal of Cardiology. 2017;240:271-8. DOI: 10.1016/j.ijcard.2017.02.150

57. Platz E, Lewis EF, Uno H, Peck J, Pivetta E, Merz AA et al. Detection and prognostic value of pulmonary congestion by lung ultrasound in ambulatory heart failure patients. European Heart Journal. 2016;37(15):1244-51. DOI: 10.1093/eurheartj/ehv745

58. Ricci F, Aquilani R, Radico F, Bianco F, Dipace GG, Miniero E et al. Role and importance of ultrasound lung comets in acute cardiac care. European Heart Journal: Acute Cardiovascular Care. 2015;4(2):10312. DOI: $10.1177 / 2048872614553166$

59. Shyamsundar M, Attwood B, Keating L, Walden AP. Clinical review: The role of ultrasound in estimating extra-vascular lung water. Critical Care. 2013;17(5):237. DOI: 10.1186/cc12710

60. Anile A, Russo J, Castiglione G, Volpicelli G. A simplified lung ultrasound approach to detect increased extravascular lung water in critically ill patients. Critical Ultrasound Journal. 2017;9(1):13. DOI: 10.1186/s13089-017-0068-x

61. Bedetti G, Gargani L, Sicari R, Gianfaldoni ML, Molinaro S, Picano E. Comparison of Prognostic Value of Echocardiacgraphic Risk Score With the Thrombolysis In Myocardial Infarction (TIMI) and Global Registry In Acute Coronary Events (GRACE) Risk Scores in Acute Coronary Syndrome. The American Journal of Cardiology. 2010;106(12):1709-16. DOI: 10.1016/j.amjcard.2010.08.024

62. Miglioranza MH, Gargani L, Sant'Anna RT, Rover MM, Martins VM, Mantovani A et al. Lung Ultrasound for the Evaluation of Pulmonary Congestion in Outpatients: a comparison with clinical assessment, natriuretic peptides, and echocardiography. JACC: Cardiovascular Imaging. 2013;6(11):1141-51. DOI: 10.1016/j.jcmg.2013.08.004

63. Brogi E, Gargani L, Bignami E, Barbariol F, Marra A, Forfori F et al. Thoracic ultrasound for pleural effusion in the intensive care unit: a narrative review from diagnosis to treatment. Critical Care. 2017;21(1):325. DOI: 10.1186/s13054-017-1897-5

64. Lichtenstein D. Novel approaches to ultrasonography of the lung and pleural space: where are we now? Breathe. $2017 ; 13(2): 100-11$. DOI $10.1183 / 20734735.004717$

65. Morales-Rull JL, Bielsa S, Conde-Martel A, Aramburu-Bodas O, Llàcer $\mathrm{P}, \mathrm{Quesada} \mathrm{MA}$ et al. Pleural effusions in acute decompensated heart failure: Prevalence and prognostic implications. European Journal of Internal Medicine. 2018;52:49-53. DOI: 10.1016/j. ejim.2018.02.004

66. Atkinson P, Milne J, Loubani O, Verheul G. The V-line: a sonographic aid for the confirmation of pleural fluid. Critical Ultrasound Journal. 2012;4(1):19. PMID: 22920298

67. Goffi A, Kruisselbrink R, Volpicelli G. The sound of air: point-of-care lung ultrasound in perioperative medicine. Canadian Journal of Anaesthesia = Journal Canadien D'anesthesie. 2018;65(4):399-416. DOI: $10.1007 / \mathrm{s} 12630-018-1062-x$

68. Tavazzi G, Neskovic AN, Hussain A, Volpicelli G, Via G. A plea for an early ultrasound-clinical integrated approach in patients with acute heart failure. A proactive comment on the ESC Guidelines on Heart Failure 2016. International Journal of Cardiology. 2017;245:207-10. DOI: $10.1016 /$ j.ijcard.2017.07.013 
69. Stolz L, O’Brien K, Miller M, Winters-Brown N, Blaivas M, Adhikari S. A Review of Lawsuits Related to Point-of-Care Emergency Ultrasound Applications. Western Journal of Emergency Medicine. 2015;16(1):1-4. DOI: 10.5811/westjem.2014.11.23592

70. Nazerian P, Volpicelli G, Gigli C, Lamorte A, Grifoni S, Vanni S. Diagnostic accuracy of focused cardiac and venous ultrasound examinations in patients with shock and suspected pulmonary embolism. Internal and Emergency Medicine. 2018;13(4):567-74. DOI: 10.1007/s11739-017-1681-1

71. Volpicelli G, Vanni S, Becattini C, Sferrazza Papa GF, Gigli C, Grifoni $S$ et al. Prediction Rule for Diagnosis of Pulmonary Embolism Enhanced by Lung and Venous Ultrasound: Making Confusion or Increasing Efficiency? Academic Emergency Medicine. 2017;24(4):498-9. DOI: 10.1111/acem.13153

72. Nazerian P, Vanni S, Volpicelli G, Gigli C, Zanobetti M, Bartolucci M et al. Accuracy of Point-of-Care Multiorgan Ultrasonography for the Diagnosis of Pulmonary Embolism. Chest. 2014;145(5):950-7. DOI: 10.1378/chest.13-1087

73. Malbrain MLNG, De Tavernier B, Haverals S, Slama M, VieillardBaron A, Wong A et al. Executive summary on the use of ultrasound in the critically ill: consensus report from the 3rd Course on Acute Care Ultrasound (CACU). Anaesthesiology Intensive Therapy. 2017;49(5):393-411. DOI: 10.5603/AIT.a2017.0072

74. Havelock T, Teoh R, Laws D, Gleeson F, BTS Pleural Disease Guideline Group. Pleural procedures and thoracic ultrasound: British Thoracic Society Pleural Disease Guideline 2010. Thorax. 2010;65(Suppl 2):ii61-76. DOI: $10.1136 /$ thx.2010.137026

75. Dancel R, Schnobrich D, Puri N, Franco-Sadud R, Cho J, Grikis L et al. Recommendations on the Use of Ultrasound Guidance for
Adult Thoracentesis: A Position Statement of the Society of Hospital Medicine. Journal of Hospital Medicine. 2018;13(2):126-35. DOI: $10.12788 / \mathrm{jhm} .2940$

76. Sicari R, Galderisi M, Voigt J-U, Habib G, Zamorano JL, Lancellotti P et al. The use of pocket-size imaging devices: a position statement of the European Association of Echocardiography. European Journal of Echocardiography. 2011;12(2):85-7. DOI: 10.1093/ejechocard/jeq184

77. Neskovic AN, Hagendorff A, Lancellotti P, Guarracino F, Varga A, Cosyns B et al. Emergency echocardiography: the European Association of Cardiovascular Imaging recommendations. European Heart Journal Cardiovascular Imaging. 2013;14(1):1-11. DOI: 10.1093/ehjci/jes 193

78. Mebazaa A, Yilmaz MB, Levy P, Ponikowski P, Peacock WF, Laribi S et al. Recommendations on pre-hospital and early hospital management of acute heart failure: a consensus paper from the Heart Failure Association of the European Society of Cardiology, the European Society of Emergency Medicine and the Society of Academic Emergency Medicine - short version. European Heart Journal. 2015;36(30):1958-66. DOI: 10.1093/eurheartj/ehv066

79. Price S, Platz E, Cullen L, Tavazzi G, Christ M, Cowie MR et al. Echocardiography and lung ultrasonography for the assessment and management of acute heart failure. Nature Reviews Cardiology. 2017;14(7):427-40. DOI: 10.1038/nrcardio.2017.56

80. Lancellotti P, Pellikka PA, Budts W, Chaudhry FA, Donal E, Dulgheru $\mathrm{R}$ et al. The clinical use of stress echocardiography in non-ischaemic heart disease: recommendations from the European Association of Cardiovascular Imaging and the American Society of Echocardiography. European Heart Journal - Cardiovascular Imaging. 2016;17(11):1191-229. DOI: 10.1093/ehjci/jew190 